\title{
Metal Kaplama Tesisi Atıksuyundan Elektrokoagülasyon Yöntemi ile Fosfat Giderimi
}

\author{
Phosphate Removal from Metal Coating Plant Wastewater by Electrocoagulation
}

\author{
Ümmükülsüm ÖZEL AKDEMİ*1,a
}

${ }^{\text {I} G i r e s u n ~ U ̈ n i v e r s i t e s i, ~ M u ̈ h e n d i s l i k ~ F a k u ̈ l t e s i, ~ I ̇ n s ̧ a a t ~ M u ̈ h e n d i s l i g ̆ i ~ B o ̈ l u ̈ m u ̈, ~ 28200, ~ G i r e s u n ~}$

\author{
• Geliş tarihi / Received: 28.04.2020 • • Düzeltilerek geliş tarihi / Received in revised form: 01.08.2020 • Kabul tarihi / Accepted: 20.09.2020
}

\section{$\ddot{O} z$}

Bu çalışmada, otomotiv sektörü metal kaplama atıksuyundan fosfat giderimi için elektrokoagülasyon (EC) yönteminin uygulanabilirliği araştırılmıştır. Çalışma, Demir (Fe) elektrot kullanılarak 25, 50, 75 ve $100 \mathrm{~mA} / \mathrm{cm}^{2}$ akım yoğunluğunda 1 saat kesikli olarak yürütülmüştür. Sonuçlar en yüksek akım yoğunluğunda fosfat giderim veriminin en yüksek \%89,5 olduğunu göstermiştir. Ancak arıtım sürecinde $30 \mathrm{dk}$ ' dan sonra elektriksel iletkenlik ve pH' da artı̧̧a bağlı olarak giderimin veriminin azalarak arttığı belirlenmiş̧ir. Ayrıca en yüksek akım yoğunluğunda, arıtımdan kaynaklanan çamurun en yüksek oranda çökeldiği ve çökelme hacminin $14 \mathrm{~mL}$ olduğu gözlemlenmiştir.

Anahtar kelimeler: Arıtım, Atıksu, Demir Elektrot, Elektrokoagülasyon, Fosfat, Giderim

\begin{abstract}
In this study, the applicability of electrocoagulation method for phosphate removal from metal coating wastewater was investigated. The experiments were performed in a batch EC reactor using Fe electrode during an hour in 25, 50, 75 ve $100 \mathrm{~mA} / \mathrm{cm}^{2}$ current density. The results showed that the highest phosphate removal efficiency was $89.5 \%$ at the highest current density. However, it was determined that the removal efficiency decreased after 30 minutes during the treatment process due to the increasing of electrical conductivity and $\mathrm{pH}$. In addition, it was observed that at the highest current density, the sludge resulting from the treatment was exposed to the highest settling and the settling sludge volume was the lowest $14 \mathrm{~mL}$.
\end{abstract}

Keywords: Treatment, Wastewater, Iron Electrode, Electrocoagulation, Phosphate, Removal

*a Ümmükülsüm ÖZEL AKDEMIR; ummukulsum.akdemir@giresun.edu.tr, Tel: (0454) 310 17 40, orcid.org/0000-0002-1318-6655 


\section{Giriş}

Fosfat bitki ve mikroorganizmaların fizyolojik prosesleri için gerekli olan temel besinlerden biridir. $\mathrm{Bu}$ nedenle fosfat sularda ortofosfat, polifosfat ve organik fosfat formunda bulunur (Bakshi vd. 2020). Yüzey sularına deşarj edilen bu fosfat formları, ötrofikasyonu hızlandırdı için, çevresel su kaynaklarının incelenmesinde en önemli problemleri oluşturur (Bektaş vd., 2004; Vasudevan vd. 2009, Sun vd. 2020). İçme suyunda alglerin aşırı büyümesine neden olan bu olay, başlıca zirai alanlarda gübre kullanımı, kentsel ve endüstriyel atıksuların çevreye deşarjı ve atmosferik çökelme gibi yüksek fosfat konsantrasyonlarından kaynaklanmaktadır (Vasudevan vd. 2009, Nassef 2012). Alıcı ortama deşarj edilen fosfat çözünmüş oksijenin azalmasına, sucul organizmaların ölümüne, su kalitesinde azalmaya bağlı olarak arıtma sistemlerinde arzalanmaya neden olur (Bakshi 2020, Sun vd. 2020). İnsan popülasyonuna paralel olarak su tüketiminin artması tüm su kaynaklarını kurtarma ve koruma çabalarını arttırmaktadır. Fosfor içeren kimyasal atıkların ve atıksuların azaltılmasının yanında, fosfat içeren atıksuların arıtılmas1 gerekmektedir (Attour vd., 2014). Deşarj limitlerine bağlı olarak fosfat arıtımında nitrifikasyon, denitrifikasyon, kırılma noktası klorlaması, kimyasal çöktürme, kristalizasyon, iyon değişimi, membran filtre, sulak alan, mikrodalga radyasyon, kapasitif deiyonize metotlar ve adsorpsiyon gibi çeşitli metotlar uygulanmaktadır (Bakshi 2020, Sun vd. 2020). Atıksulardan fosfat gideriminde fiziksel, kimyasal ve biyolojik metotlar çok yaygın bir şekilde kullanılmasına rağmen, bu metotlar kendi içlerinde değerlendirildiğinde birçok dezavantaja sahiptirler (Stafford vd. 2014). Elektrodiyaliz veya ters osmoz gibi fiziksel yöntemler, çok pahalıdır ve toplam fosfatın sadece \%10' u gibi düşük bir giderim verime sahiptir (Vasudevan vd. 2009, Chen vd. 2014). Kimyasal çökelme ile fosfat gideriminde alüminyum sülfat ve demir klorür çok yaygın kullanılır (Bektaş vd., 2004). $\mathrm{Bu}$ yöntem, yüksek bakım maliyeti ve genelde kimyasal çöktürücülerin fosfat giderimi için önerilen teorik stokiyometri seviyesinin üstünde uygulanarak yüksek çamur üretimi ve bertaraf maliyetleri gibi dezavantajlara sahiptir (Bektaş vd. 2004, Attour vd. 2014). Ayrıca, işlem süresince kalsiyum ile çöktürme için alkali koşul gereklidir ve alüminyum ve demir kullanılırsa, asidik ortamları nötralize etmek gerekir. Bu sadece kimyasal maliyetini arttırmakla kalmaz, ayn zamanda biyolojik arıtma işlemlerine de zarar verir (Bektaş vd., 2004). Biyolojik metotlar, uygun maliyetli ve fiziksel ve kimyasal süreçlerden daha az çamur üretir. Ancak, bu yöntemde ise arıtma süresi daha uzundur ve düşük fosfat giderimi söz konusudur (Chen vd. 2014). Biyolojik süreçlere ise, fosfatın sıvıdan çamur fazına aktarılması gerekmekte ve bu durumda, uzaklaştırma verimi genellikle \%30' u aşmamaktadır. $\mathrm{Bu}$ nedenle kalan fosfatın başka tekniklerle uzaklaştırılması gerekmektedir (Vasudean vd. 2009).

Eelektrokoagülasyon (EC) bu konvansiyonel proseslere bir alternatif olarak atıksu arıtımında büyük ilgi görmektedir. Bu yüzden, son yıllarda organik bileşikler, ağır metaller, anyonlar (nitrat, florür ve fosfat gibi) gibi farklı türlerde kirleticilerin ve sertlik gideriminde, boya ve tekstil atıksuyu, süt endüstrisi atıksuyu, biyodizel atıksuyu ve petrol rafinerisi atıksuyu arıtımında başarılı bir şekilde kullanılmaktadır (Behbahami vd. 2011). Elektrokoagülasyon, çökelme ve koagülasyon mekanizmaları yoluyla kirleticileri uzaklaştıran, yerinde koagulant üretimi için (metal iyonları üretmek için) verici metal elektrotlar boyunca elektrik akımı geçiren bir işlemdir (Stafford vd., 2014, Lacasa vd., 2011). Lacasa vd. (2011) EC prosesinin fosfat giderim mekanizmas1 Şekil 1' deki gibi özetlemiştir.

EC metodu kimyasal metotlara göre, daha az koagülant iyonu gerektirmesi, kimyasal ilavesi gerektirmemesi, oldukça küçük alana ihtiyaç duyması, düşük yatırım maliyeti ve kolay işletilebilmesi, daha az çamur üretmesi, kısa alıkonma süresine sahip olması ve daha büyük floklara sahip olması ile karakterize edilir. Ayrıca daha kararlı oldukları için filtrasyona da müsaittirler (Bektaş vd. 2004, Inan ve Alaydın 2014). Diğer yandan, proses verimi elektrik voltaj1, iyonik konsantrasyon, elektrot materyali ve alıkonma süresi ve sıcaklığı gibi faktörlere bağlı olduğu için bu faktörleri optimize etmek prosesin başarısında önemli rol oynamaktadır (Inan ve Alaydın 2014).

$\mathrm{Bu}$ çalışmada metal kaplama tesisinden alınan fosfatlı atıksuyun elektrokoagülasyon ile giderimi farklı akım şartları altında araştırılmıştır ve fosfat giderimi esnasında elektriksel iletkenlik, $\mathrm{pH}$ değişimi ve çamur oluşumu belirlenmiştir. 


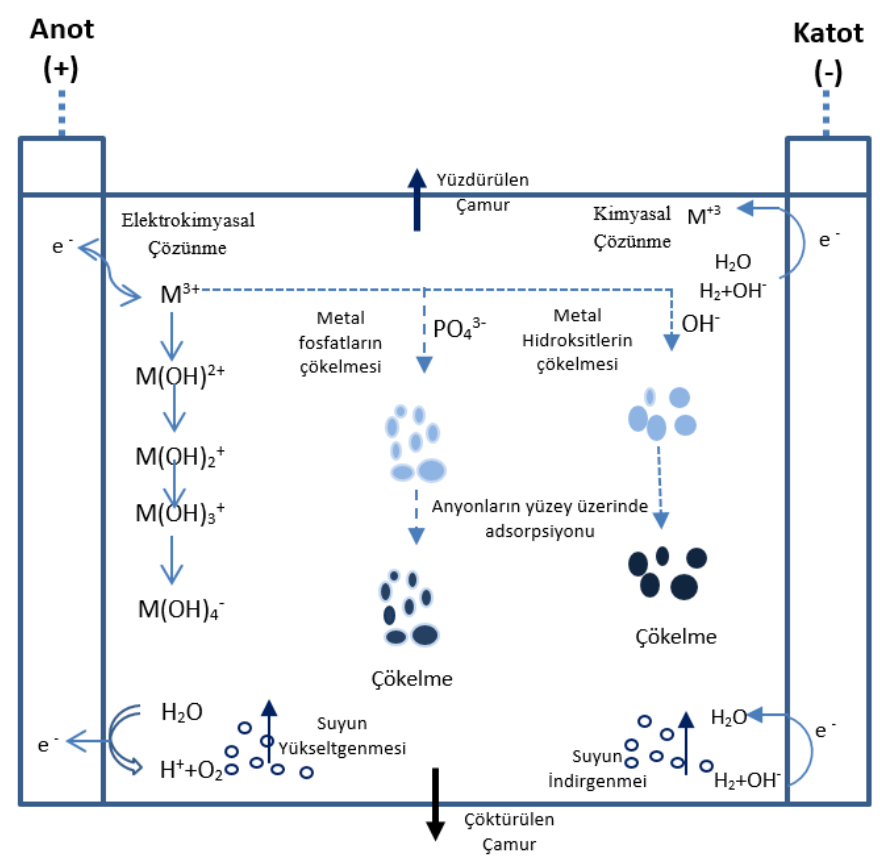

Şekil 1. Elektrokoagülasyonla fosfat gideriminin mekanizması (Lacasa vd. (2011) den düzenlenmiştir

\section{Materyal ve Metot}

Çalışmada kullanılan atıksu Samsun organize sanayinde yedek parça üreten Sampa Otomotiv A.Ş’ den alınmıştır. Atıksu tesiste yüzey işleme ünitesi 1.durultucu tankından alınmıştır. Bu ünite Yarı Mamul, Yağ Alma, Kumlama, Yüzey İşlem ve Boya ünitelerinden oluşmaktadır. Alınan atıksuya ait karakter analizi Tablo 1' de verilmiştir.

Tablo 1. Metal kaplama tesisi atıksu özellikleri

\begin{tabular}{lc}
\hline \multicolumn{1}{c}{ Parametre } & Değer \\
\hline $\mathrm{pH}$ & 5.3 \\
Sicaklik $\left({ }^{\circ} \mathrm{C}\right)$ & 20 \\
Elektriksel İletkenlik $(\mu \mathrm{S} / \mathrm{cm})$ & 850 \\
$\mathrm{PO}_{4}{ }^{-}(\mathrm{mg} / \mathrm{L})$ & 54.7 \\
$\mathrm{KOI}(\mathrm{mg} / \mathrm{L})$ & 175 \\
\hline
\end{tabular}

Arıtımda kullanılan elektrokoagülasyon reaktör pleksiglas malzemeden üretilmiştir. Reaktörün boyutlar1 $6.45 \mathrm{~cm} \times 9.95 \mathrm{~cm} \times 11.2 \mathrm{~cm}$ olarak tasarlanmıştır. Reaktörde 3 adet demir elektrot (anot) ve 3 adet Çelik (S) elektrot (Katot) kullanılmıştır. Elektrot boyutları $4.5 \mathrm{~cm}$ x $7.33 \mathrm{~cm}$ x $0.25 \mathrm{~cm}$ dir. Elektrotlar arasi mesafe $0.6 \mathrm{~cm}$ dir. Elektrotlar reaktör içerisine paralel bağli monopolar olarak bağlanmıştır. Reaktörlere 610 $\mathrm{mL}$ atıksu eklenerek elektrotların su içerisinde kalması sağlanmıştır. Sistemde doğru akım için GW marka GPS-3060D model DC güç kaynağ kullanılmıştır. Reaktörde arıtım için karışım, 2.5 $\mathrm{cm} \times 0.75 \mathrm{~cm}$ ebatlarındaki pedallı VELP marka JLT 6 model jar testi ile $200 \mathrm{rpm}$ de yapılmıştır.
Arıtım kesikli olarak yapılmış olup, 25, 50, 75 ve $100 \mathrm{~mA} / \mathrm{cm}^{2}$ akım yoğunluğuna karş1lık gelen akım EC deney düzeneğine verilmiştir.

Reaktör içerisinden $2,5,10,20,30,40,50$ ve 60 dakika sonunda $5 \mathrm{~mL}$ numune alınarak örnekler çökelmeye bırakıldıktan sonra berrak kısımlarına fosfat tayini yapılmıştır. Reaktörün bu zaman aralıklarında elektriksel iletkenliği ve $\mathrm{pH}$ ölçümleri, Thermo Scientific Orion 3-Star marka pH multi parametre ile ölçülmüsşür. Fosfat tayini EPA 365.2+3, APHA 4500-P E, ve DIN EN ISO 6878 standartlarına uygun olan Merck reagent test (1.00798.0001) ile Nova 60 fotometre ile gerçekleştirilmiştir.

\section{Bulgular ve Tartışma}

Faklı akım yoğunlukları için 1 saat süreyle kesikli elektrokoagülasyon deneyleri gerçekleştirilmiştir. Şekil 2' de farklı akım yoğunluklarında fosfat konsantrasyonu değişimi görülmektedir. Giriş $\mathrm{PO}_{4}^{-3}$ konsantrasyonu $54.7 \mathrm{mg} / \mathrm{L}$ olan attk suyun 60 dakikalı arıtım neticesinde $\mathrm{PO}_{4}{ }^{-}$ konsantrasyonu en düşük $\left(25 \mathrm{~mA} / \mathrm{cm}^{2}\right)$ akım yoğunluğunda $9.3 \mathrm{mg} / \mathrm{L}$ olarak gerçekleşmiştir. Yüksek akım yoğunluğu, yüksek fosfat giderimini sağlamıştır. Sonuçlar, Kopya vd. 2010 ve Franco vd. 2017 tarafindan yapılan diğer çalışmaların sonuçlarını desteklemektedir. 


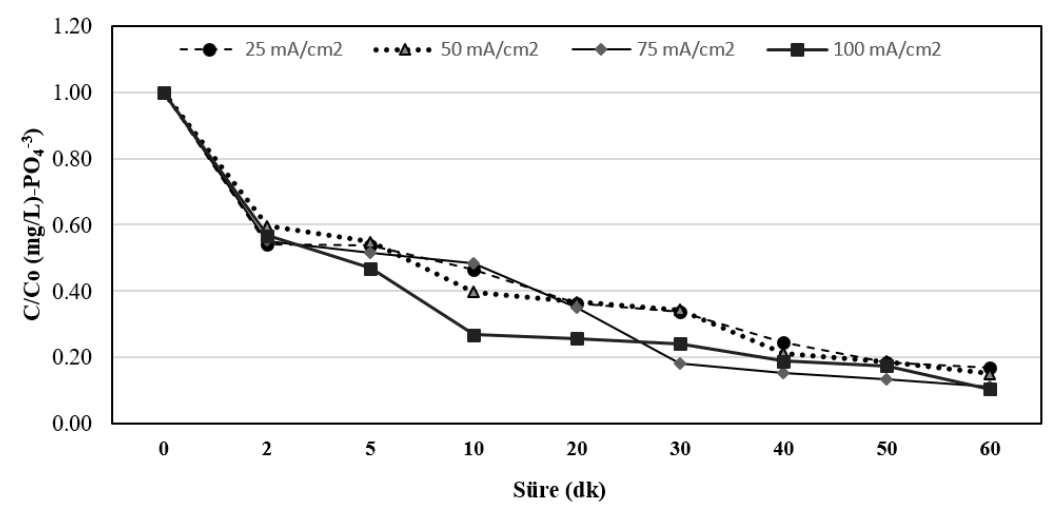

Şekil 2. Farklı akım yoğunluklarında fosfat giriş ve çıkış konsantrasyon oranlarının değişimi

$25 \mathrm{~mA} / \mathrm{cm}^{2}, 50 \mathrm{~mA} / \mathrm{cm}^{2}, 75 \mathrm{~mA} / \mathrm{cm}^{2}$ ve 100 $\mathrm{mA} / \mathrm{cm}^{2}$ lik akım yoğunluklarında yapılan deneysel çalışmalara ait \% giderim verimleri Şekil 3' de gösterilmiştir. Akım yoğunluğundaki artış fosfat gideriminde de artışa neden olmuştur. 60 dakika sonunda; en yüksek fosfat giderim verimi $\% 89.57$ ile $100 \mathrm{~mA} / \mathrm{cm}^{2}$ de gerçekleşirken, en düşük fosfat giderim verimi $\% 83$ ile $2.5 \mathrm{~mA} / \mathrm{cm}^{2}$ lik akım yoğunluğunda gerçekleşmiştir (Şekil 3). Arıtım sonunda (60. dk) farklı akım yoğunluklarında giderim verimlerinin çok yakın olduğu görülmektedir. Ancak 75 ve $100 \mathrm{~mA} / \mathrm{cm}^{2}$ yüksek akım yoğunlukları için 30 . dk dan sonra arıtım veriminin azalan bir artış gösterdiği belirlenmiştir.

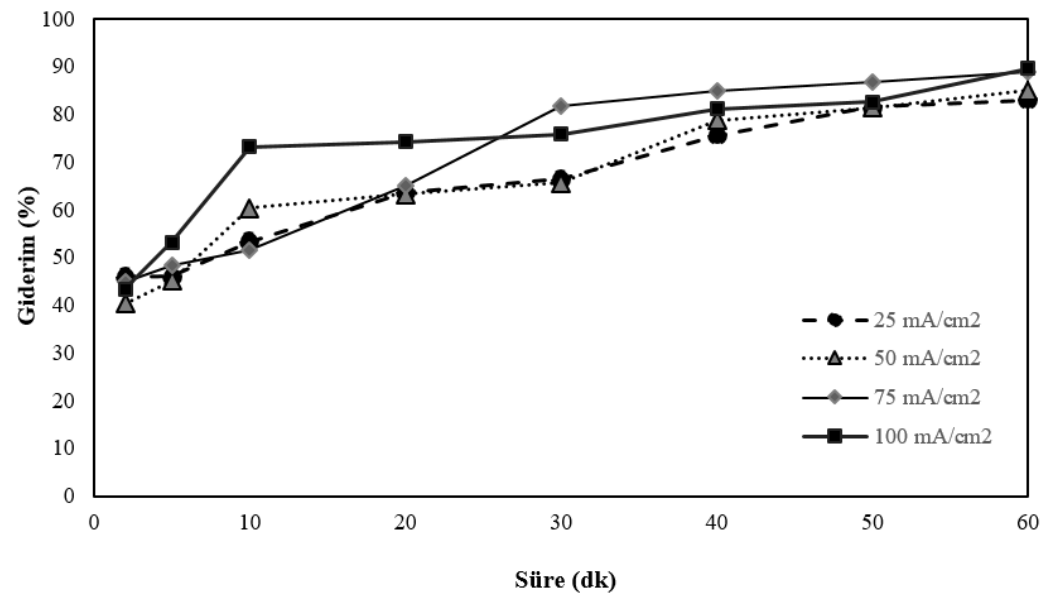

Şekil 3. Farklı akım yoğunlukları için $\mathrm{PO}_{4}{ }^{-}$giderimi

Behbahani vd. (2011) Fe elektrot ile yapmış oldukları çalışmada, en yüksek arıtım veriminin elde edildiği 3 ve 7 giriş pH' sinda en yüksek 7.2 ve 10.5 çıkış pH' sına ulaşıldığını göstermişlerdir. Akım yoğunluğundaki artış fosfat giderim veriminde de artışa neden olmakla birlikte sınırlayıcı etmen $\mathrm{pH}$ dır. Şekil 4-a' da farklı yoğunluklarında arıtımın 30 . dk' sinda $\mathrm{pH}$ 10.110.63 arasında değiştiği görülmektedir.

Yüksek pH değerlerinde oksitlenen yüzey net negatif yükle kapanır ve anyonik fosfat itme eğilimi gösterir. Çözünmeyen metal hidroksitleri, pH' in artışından dolayı meydana gelir ve demir hidroksitleri ilk önce oluşur. Numunedeki $\mathrm{OH}^{-}$ iyonları arttığından dolayı elektriksel iletkenlik artışı ile $\mathrm{pH}$ artar. Asidik şartlardaki $\mathrm{pH}$ artışı katyonda Hidrojen iyonu oluşumuna katkı sağlar. EC prosesindeki $\mathrm{pH}^{\prime}$ in bu değişimi, suyun elektrolizi ve koagülasyon prosesinin kimyası ile ilişkilidir. Bu nedenle proses yüksek elektriksel yük uygulaması altında olduğundan başlangıçtaki fosfor giderim safhası komplekstir. Belli bir süre sonra anot tarafından tüketilen hidroksit $\left(\mathrm{OH}^{-}\right)$ iyonu karşılanamadığı için $\mathrm{pH}$ artışı sabit hale gelir. Oluşan $\mathrm{OH}^{-}$iyonu yeterli olmaz. Sürekli çökelme için $\mathrm{OH}$ iyonları kullanıldığından pH 30 dakikadan sonra sınırlanabilir değerde kalmıştır (Şekil 4 ve 5). Optimum bekletme süresinden sonra (yaklaşık 30-40 dakika) $\mathrm{pH}$ düzeyi stabil hale gelmiştir. $\mathrm{Bu}$ durum tüm akım değerleri için geçerlidir. 


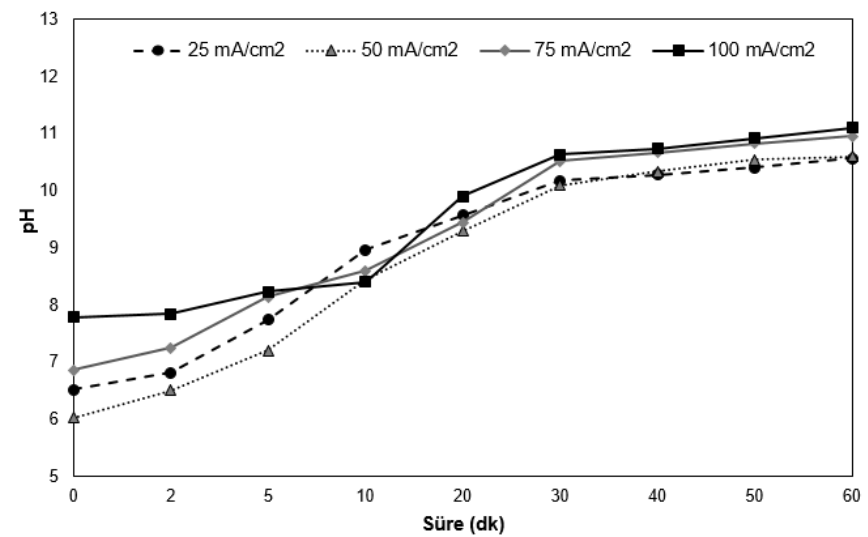

(a)

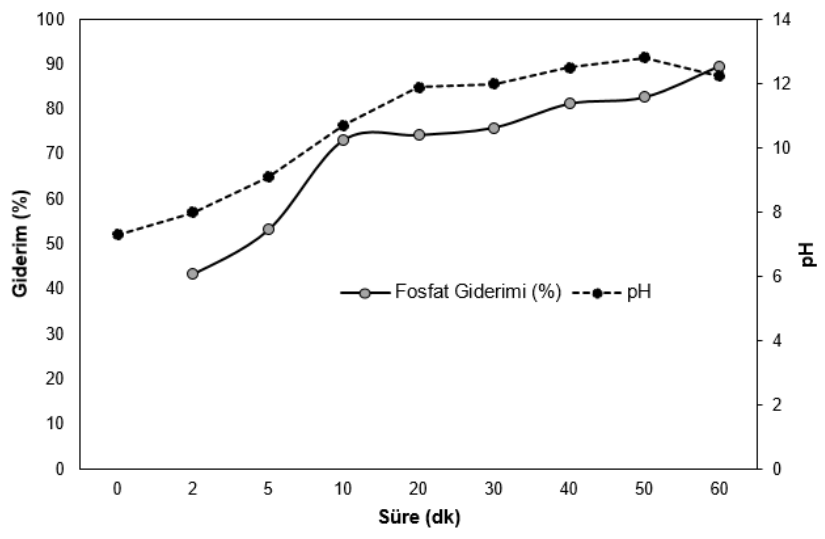

(b)

Şekil 4. (a) Farklı akım yoğunluklarında zamana bağlı pH değişimi, (b) En yüksek giderim veriminde zamana bağlı $\mathrm{pH}$ değişimi

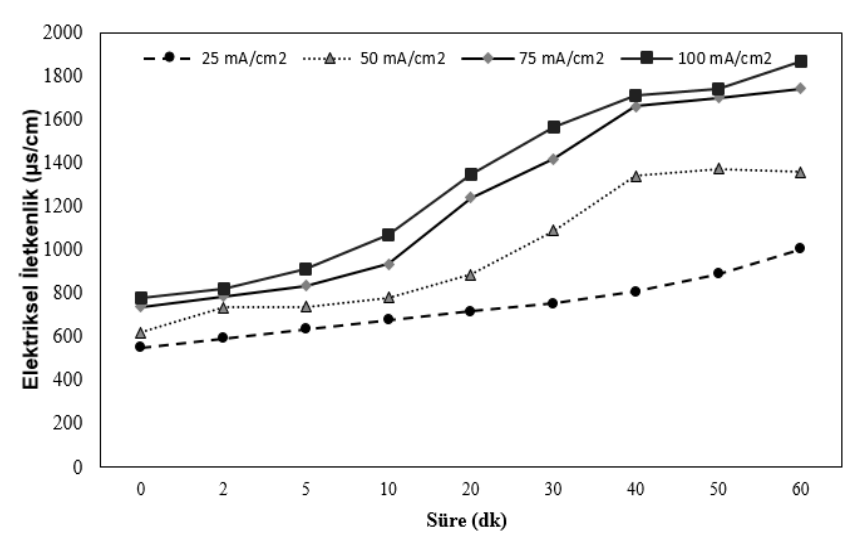

(a)

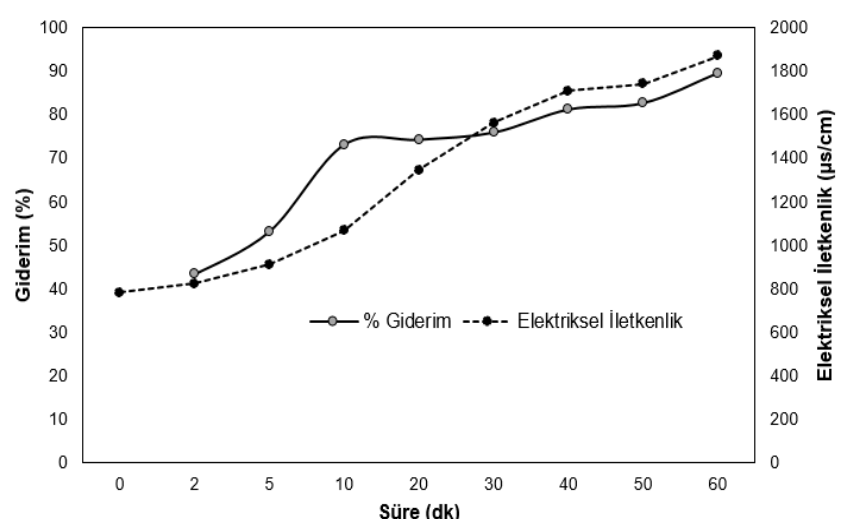

(b)

Şekil 5. (a) Farklı akım yoğunluklarında zamana bağlı elektriksel iletkenlik değişimi, (b) En yüksek giderim veriminde zamana bağlı elektriksel iletkenlik değişimi

Tablo 2. Elektrokoagülasyon ile fosfat giderimleri ile ilgili diğer çalışmalar

\begin{tabular}{|c|c|c|c|c|c|c|c|}
\hline Atıksu Türü & Elektrotlar & $\begin{array}{c}\mathrm{Co}\left(\mathrm{PO}_{4}^{-3}\right) \\
(\mathrm{mg} / \mathrm{L})\end{array}$ & $\underset{\substack{\text { Akım } \\
\text { Yoğunluğu }}}{\text {. }}$ & $\begin{array}{l}\text { Reaksiyon } \\
\text { Süresi } \\
\text { (dk) }\end{array}$ & pH & $\begin{array}{c}\text { Giderim } \\
(\%)\end{array}$ & Kaynak \\
\hline Ham Atıksu & Çelik-Çelik & $10-50$ & $0.5 \mathrm{~mA} / \mathrm{cm}^{2}$ & 20 & 6.5 & 98.5 & Vasudevan vd. 2008 \\
\hline İçme suyu & Zn-Çelik & $10-40$ & $0.05 \mathrm{~A} / \mathrm{dm}^{2}$ & 30 & 7 & 98.8 & Vasudevan vd.2009 \\
\hline Sentetik & $\mathrm{Fe}-\mathrm{Fe}$ & 5 & $0.8 \mathrm{~mA} / \mathrm{cm}^{2}$ & 55 & 5.2 & 89.2 & Dian vd. 2013 \\
\hline Sentetik Atıksu & $\mathrm{Al}-\mathrm{Fe}$ & 110 & $8 \mathrm{~mA} / \mathrm{cm}^{2}$ & 60 & 8 & 99 & Chen vd. 2014 \\
\hline Sentetik Atıksu & $\begin{array}{l}\mathrm{Al}-\mathrm{Al} \\
\mathrm{Fe}-\mathrm{Fe}\end{array}$ & 50 & $1 \mathrm{~mA} / \mathrm{cm}^{2}$ & 40 & - & $\begin{array}{l}98.9 \\
93.5 \\
\end{array}$ & Duricic vd.2016 \\
\hline Ham Atıksu & Grafit-Al & 20 & $1 \mathrm{~mA} / \mathrm{cm}^{2}$ & 15 & 7 & 98 & Tian vd.2016 \\
\hline Sentetik Atıksu & $\mathrm{Al}-\mathrm{Al}$ & $\begin{array}{c}0.07-1.75 \\
(\mathrm{TP})\end{array}$ & (1) & $50-60$ & 5 & 99 & Franco vd. 2017 \\
\hline Sentetik Atıksu & $\mathrm{Al}-\mathrm{Al}$ & $25-100$ & $10 \mathrm{~mA} / \mathrm{cm}^{2}$ & 120 & 7 & 97.65 & Tibebe vd.2019 \\
\hline Sentetik Atıksu & Fe-Çelik & 500 & $11.7 \mathrm{~mA} / \mathrm{cm}^{2}$ & 60 & 5 & 92 & Dura vd.2019a \\
\hline Ham Atıksu & $\mathrm{Al}-\mathrm{Al}$ & 100 & $6 \mathrm{~mA} / \mathrm{cm}^{2}$ & 60 & 6 & 99 & Hashim vd. 2019 \\
\hline Ham Atıksu & $\mathrm{Al}-\mathrm{Mg}$ & 20 & $5 \mathrm{~mA} / \mathrm{cm}^{2}$ & 20 & 5 & 95 & Dura vd.2019b \\
\hline Ham atıksu & Fe-Çelik & 54.7 & $100 \mathrm{~mA} / \mathrm{cm}^{2}$ & 60 & 7.29 & 89.57 & Bu Çalışma \\
\hline
\end{tabular}

$\mathrm{Bu}$ çalışmadan elde edilen fosfat giderim verimlerinin farklı metal elektrotların kullanıldığ fosfat giderimi ile ilgili diğer çalışmaların karşılaştırmalı hali Tablo 2' de verilmiştir. Yapılan çalışmalarda Fe elektrot kullanımında Al elektrot kullanımına göre daha düşük fosfat giderimi sağladığı bildirilmiştir (Duricic vd.2016). Fe elektrot kullanılan bu çalışmada arıtım veriminin \%89,57 olmasinın elektrot seçiminden kaynaklandığı görülmektedir. 


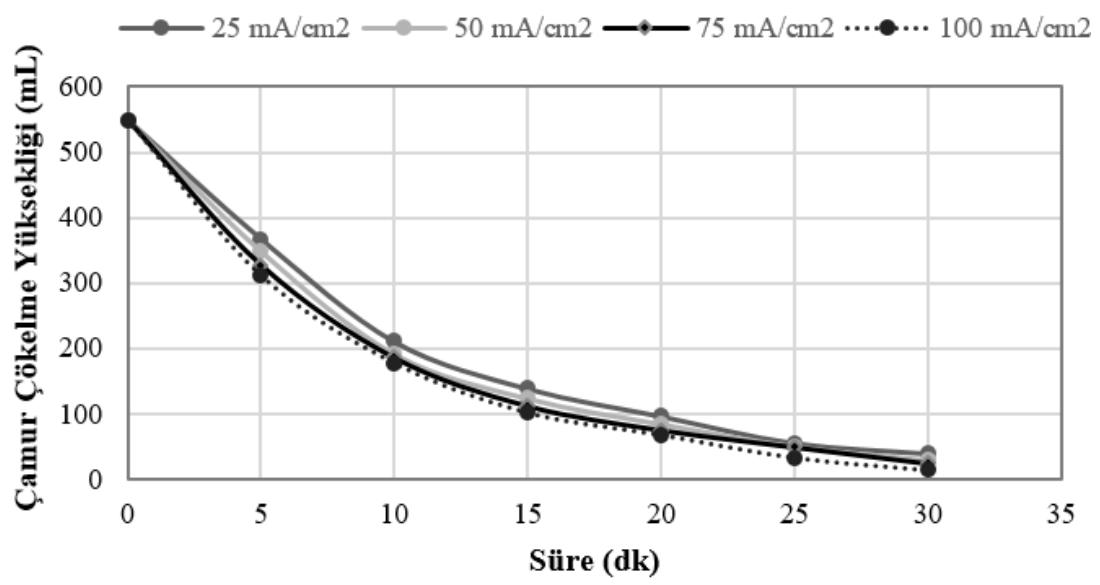

Şekil 6. Farklı akım yoğunluklarında oluşan çamur miktarları

Akım yoğunluklarına bağlı olarak oluşan çamur miktarları Şekil 6' da verilmiştir. EC prosesi ile oluşan çamur kolayca çökelebilir ve susuzlaştırılabilir. Akım yoğunluğuna karşılık gelen çamurun çökelme miktarı Şekil 6' da verilmiştir. Akım yoğunluğunun artışı ile hacim olarak çökelmiş çamur miktarının daha az olduğu ancak hemen hemen birbirine yakın olduğu görülmektedir (Şekil 6). Akım yoğunluğundaki artış ile kabarcık yoğunluğu artarken kabarcık büyüklüğü azalmaktadır. Bunun kabarcıkların çökelmesi üzerinde olumsuz bir etkisinin olacağ düşünülmesine rağmen artan akım yoğunluğu ile anotta daha fazla demir çözüneceğinden daha yüksek koagulasyon performansı gözlenecektir. $\mathrm{Bu}$ durum $100 \mathrm{~mA} / \mathrm{cm}^{2}$ akım yoğunluğunda çamur çökelme yüksekliğinin daha düşük olması ile açıklanmaktadır. Arıtım esnasında oluşan flokların büyüklüğü, daha fazla çamurun çökelmesini sağlayacağ 1 için arıtım sonrası bekleme süresi ve çamur depolama yerinin tasarımında önemli olacaktır.

Akım yoğunluklarının arıtımı verimine etkisinde aralarındaki benzerliği belirlemek için Ward Linkage, Euclidean Distance metodu ile kümele analizi yapılmıştır. Şekil 7' de yatay eksen farklı akım yoğunluklarını düşey eksen ise fosfat giderim verimleri vermektedir. Kümeleme analizinde akım yoğunlukları kümelemesi içerisinde giderim verimlerine bağlı olarak düşük akım yoğunluklarının birbiri içerisinde benzer olduğu akım yoğunlukları arttıkça kümelemenin zayıfladığı görülmektedir. $100 \mathrm{~mA} / \mathrm{cm}^{2}$ nin tek başına tek bir grup oluşturduğu, 25,50 ve 75 $\mathrm{mA} / \mathrm{cm}^{2}$, nin kendi içinde gruplandığ görülmüştür.

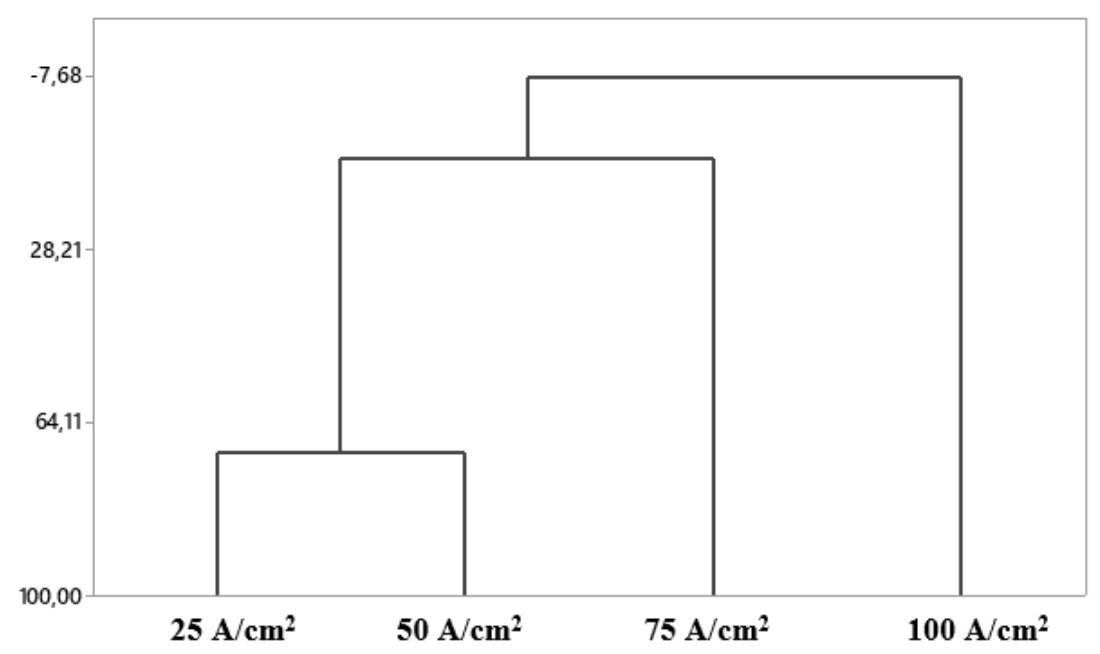

Şekil 7. Akım yoğunluklarına göre dendogram gösterimi

Akım yoğunluğunun elektrokoagülasyonun en hassas işletme parametresi olduğu düşünülürse, yüksek akımda arıtım daha hızlı gerçekleşmektedir. Çünkü yüksek akımda daha fazla hidrojen gazı çıkışı gerçekleşir ve oluşan küçük kabarcık halindeki hidrojen gazı flotasyon ile fosfat gideriminde artışa neden olur. Ayrıca pH artıkça $\mathrm{OH}^{-}$oluşumu katotta artar ve akım 
yoğunluğu da bundan etkilenir. Düşük akım yoğunluklarında anot yüzeyinde beyaz bir tabaka oluşurken yüksek akım yoğunluklarında bu tabaka oluşmaz. Hidrojen anyonlarının oluşumu hassas olduğu için katottaki kimyasal korozyon oluşumu yüksek akım yoğunlukları için açıklanabilir (Attour vd. 2014). Enerji tüketiminin akım yoğunluğu ile doğru orantılı olduğunu bilinmektedir. Optimum akım yoğunluğunun bulunması, EC' nin klasik kimyasal arıtım metodu olarak kullanılabilmesi ve düşük maliyet için önemlidir.

\section{Sonuçlar}

$\mathrm{Bu}$ çalışmada farklı akım yoğunlukları dikkate alınarak elektrokoagülasyon ile fosfor giderim performansları incelenmiştir. Elektroliz süresi arttıkça atıksudaki fosfat konsantrasyonu azalmaktadır. Akım ve bekleme süresindeki değişiminin fosfat giderimine etkisi olduğu görülmüştür. Sonuçlar, yüksek elektriksel iletkenliğin artışı ile fosfat gideriminin arttığını göstermiştir. $25,50,75$ ve $100 \mathrm{~mA} / \mathrm{cm}^{2}$ akım yoğunluklarında sirasıyla $\% 83,85,88.85$ ve 89.57 fosfat giderimi sağlamıştır. Giderim verimlerinin çok yakın olması sebebi ile en uygun akım yoğunluğu $75 \mathrm{~mA} / \mathrm{cm}^{2}$ olarak belirlenmiştir.

\section{Kaynaklar}

Attour, A., Touati, M., Tlili, M., Ben Amor, M., Lapicque, F. ve Leclerc J.P., 2014. Influence of Operating Parameters on Phosphate Removal from Water by Electrocoagulation Using Aluminum Electrodes. Seperation and Prufication Technology, 123, 124-129.

Bakshi, A., Verma, A.K. ve Dash, A.K., 2020. Electrocoagulation for Removal of Phosphate from Aqueous Solution: Statistical Modeling and Techno-Economic Study. Journal and Cleaner Production, 246. doi.org/10.1016/j.jclepro.2019.118988

Bektaş, N., Akbulut, H., İnan, H. ve Dimoglo A., 2004. Removal of Phosphate from Aqueous Solution by Electro-Coagulation. Journal of Hazardous Materials, 106B, 101-105.

Behbahani, M., Alavi Moghaddam, M.R. ve Arami M., 2011. A Comparison Between Aluminum and Iron Electrodes on Removal of Phosphate from Aqueous Solution by Electrocoagulation Process. International Journal of Environmental Research, 5, 2, 403-412.

Chen, S., Shi, Y., Wang, W., Li, Z., Gao, J. ve Bao K., 2014. Phosphorus Removal from Continuous Phosphate-Contaminated Water by Electrocoagulation Using Aluminum and Iron
Plates. Seperation Science and Technology, 49, 939-945.

Dian, K.M., Zhang, B., Feng, C. ve Cellou, K., 2013. Phosphorus Removal from Wastewater by Electrocoagulation Using Iron Electrode. Advanced Materials Research, 726-731, 24982501.

Dura, A. ve Breslin, C.B., 2019a. Electrocoagulation Using Stainless Steel Anodes: Simultaneous Removal of Phosphates, Orange II And Zinc Ions. Journal of Hazardous Materials, 379, 152158.

Dura, A. ve Breslin C.B., 2019b. The Removal of Phosphates Using Electrocoagulation with Al$\mathrm{Mg}$ Anodes. Journal of Electroanalytical Chemistry, 846, 223161, 1-8.

Duricic, T., Malinovic, B.N. ve Bijelic, D., 2016, The Phosphate Removal Efficiency Electrocoagulation Wastewater Using Iron and Aluminum Electrodes. Bulletin of the Chemists and Technologists of Bosnia and Herzegovina, 47, 33-38.

Franco, D., Lee, J., Arbelaez, S., Cohen, N. ve Kim, J.Y., 2017. Removal of Phosphate from Surface and Wastewater via Electrocoagulation. Ecological Engineering, 108, 589-596

Hashim, K.S., Khaddar, R.A., Jasim, N., Shaw, A., Phipps, D., Kot, P., Pedrola, M.O., Alattabi, A.W., Abdulredha, M. ve Alawsh, R., 2019. Electrocoagulation as a Green Technology for Phosphate Removal from River Water. Separation and Purification Technology, 210, 135-144.

Inan E. ve Alaydın E., 2014. Phosphate and Nitrogen Removal by Iron Produced in Electrocoagulation Reactor. Desalination and Water Treatment, 52, 1396-1403.

Kobya, M., Demirbas, E., Dedeli, A. ve Sensoy, M.T. 2010. Treatment of Rinse Water From Zinc Phosphate Coating by Batch and Continuous Electrocoagulation Processes. Journal of Hazardous Materials, 173, 326-334.

Lacasa, E., Canizares, P., Saez, C., Fernandez, F.J. ve Rodrigo, M.A, 2011. Electrochemical Phosphates Removal Using Iron and Aluminium Electrodes. Chemical Engineering Journal, 172, 137-143.

Nassef E., 2012. Removal of Phosphorous Compounds by Electrochemical Technique. Engineering Science and Technology: An International Journal, 2, 3, 403.

Sun, D., Hong, X., Wu, K., Hui, K.S., Du, Y. ve Hui, K.N. 2020. Simultaneous Removal of Ammonia 
and Phosphate by Electrooxidation and Electrocoagulation Using Ruo2erro2/Ti and Microscale Zero-Valent İron Composite Electrode. Water Resource, 169, 115239, 1-11.

Stafford, B., Dotro, G., Vale, P., Jefferson, B. ve Jarvis, P., 2014. Removal of Phosphorus from Tricling Filter Effluent by Electrocoagulation. Environmental Technology, 35, 24, 3139-3146

Tian, Y., He, W., Zhu, X., Yang, W., Ren, N. ve Logan, B.E., $2017 . \quad$ Improved Electrocoagulation Reactor for Rapid Removal of Phosphate from Wastewater. ACS Sustainable Chemistry \& Engineering, 5, 67-71.

Tibebe, D., Kassa, Y. ve Bhaskarwar, A.N., 2019. Treatment and Characterization of Phosphorus from Synthetic Wastewater Using Aluminum Plate Electrodes in the Electrocoagulation Process. BMC Chemistry, 13, 107, 1-14.

Vasudevan, S., Sozhan, G., Ravichandran, S., Jayaraj, J., Lakshmi, J. ve Sheela, S.M., 2008. Studies on the Removal of Phosphate from Drinking Water by Electrocoagulation Process. Industrial \& Engineering Chemistry Research, 47, 6, 2018-2023.

Vasudevan, S., Lakshmi, J. ve Sozhan, G., 2009. Optimization of the Process Parameters for the Removal Of Phosphate from Drinking Water by Electrocoagulation. Desalination and Water Treatment, 12, 407-414. 